\title{
EL DERECHO A LA OBJECIÓN DE CONCIENCIA: CRITERIOS PARA SU INTERPRETACIÓN*
}

\author{
The Right to Conscientious \\ OBJECTION: CRITERIA FOR \\ INTERPRETATION
}

O DIREITO À OBJEÇÃO DE CONSCIÊNCIA:
CRITÉRIOS PARA SUA INTERPRETAÇÃO

MARÍA MARTA DIDIER**

* $\quad$ Este artículo es el resultado parcial del proyecto de investigación titulado "Derecho a la igualdad y objeción de conciencia”, financiado por la Universidad Católica de Santa Fe (Argentina).

** Universidad Católica de Santa Fe y Universidad Católica. Argentina. mdidier@ius.austral.edu.ar

RECIBIDO: 17 DE MARZO dE 2015. EnVío A PARES: 19 DE MARZO DE 2015 APROBADO POR PARES: O2 DE MAYO DE 2015. ACEPTADO: 17 DE MAYO DE 2015

DOI: 10.5294/DIKA.2015.24.2.3 


\section{RESUMEN}

Se plantea que el principio de razonabilidad constituye una vía posible para determinar cuándo la objeción de conciencia consiste en el ejercicio regular de un derecho, fundamentándose para ello en la filosofia jurídica, en la teoría de los derechos fundamentales y en la práctica jurisprudencial. Finalmente, se propone un test de constitucionalidad aplicable a las reglamentaciones del derecho a la objeción de conciencia en el ordenamiento jurídico argentino.

\section{PALABRAS CLAVE}

Objeción de conciencia; libertad religiosa y de conciencia; razonabilidad; proporcionalidad; igualdad; discriminación; razonabilidad práctica. 


\begin{abstract}
The study argues that the principle of reasonableness is possibly one way to determine when conscientious objection constitutes the regular exercise of a right based on legal philosophy, the theory of fundamental rights and jurisprudential practice. A constitutionality test applicable to the regulations on the right to conscientious objection in the Argentine legal system is proposed by way of conclusion.
\end{abstract}

\title{
KEYWORDS
}

Conscientious objection; freedom of religion and conscience; reasonableness; proportionality; equality; discrimination; practical reasonableness. 


\section{RESUMO}

Propõe-se que o princípio da razoabilidade constitui uma via possivel para determinar quando a objeção de consciência consiste no exercício regular de um direito, fundamentando-se para isso na filosofia jurídica. Finalmente, propõe-se um teste de constitucionalidade aplicável às regulamentações do direito à objeção de consciência no ordenamento jurídico argentino.

\section{PALAVRAS-CHAVE}

Objeção de consciência; liberdade religiosa e de consciência; razoabilidade; proporcionalidade; igualdade; discriminação; razoabilidade prática. 
Sumario: Introducción; 1. El principio de Razonabilidad y El derecho a La objeción de CONCIENCIA; 1.1. EL JUICIO dE ADECUACIÓN; 1.2. EL JUICIO DE NECESIDAD; 1.3. EL JUICIO DE PROPORCIONALIDAD EN SENTIDO ESTRICTO; 1.4. El JUICIO DE AFECTACIÓN O ALTERACIÓN DEL CONTENIDO ESENCIAL; 2. La carga de la justificación; 3. El test de constitucionalidad aplicable; 4. ConcluSIONES; Bibliografía.

\section{INTRODUCCIÓN}

La objeción de conciencia ha sido considerada como una forma de desobediencia al derecho, aunque esta denominación no parece del todo precisa cuando su ejercicio debe ser reconocido como un derecho humano y constitucional. ${ }^{1}$ En tales supuestos, más que como una forma de desobediencia al derecho, estariamos ante un caso de desobediencia a la norma positiva de rango constitucional, legal, reglamentario o convencional. Ello, por cuanto resultaria contradictorio sostener que asiste un "derecho" de desobedecer el "derecho". Más exactamente, cuando la objeción de conciencia se ejerce de modo regular o razonable, lo que se desobedece es la norma positiva que estatuye la obligación, pero se actúa conforme a derecho. Obviamente, ello supone la total negación de las tesis sostenidas en el Estado de derecho legal, ${ }^{2}$ así como un concepto de derecho que no se reduce a las normas, sino que se integra a los principios jurídicos, y cuyo analogado principal, según el realismo jurídico clásico, es lo justo, entendido como la obra o conducta justa o jurídica, ${ }^{3}$ como la relación debida entre la cosa y el titular, ${ }^{4}$ o como una proporción en la repartición de bienes entre los miembros de un grupo. ${ }^{5}$

En efecto, "la objeción de conciencia se trata de un conflicto estrictamente jurídico, entre el concepto mayoritario del mínimo ético indispensable - característico de lo jurídico- que se ha visto plasmado en el texto legal, y el concepto minoritario esgrimido por el objetor". ${ }^{6}$

La justificación iusfilosófica de la objeción de conciencia puede ser esgrimida desde diversas perspectivas. Desde una visión iusnaturalista, como la del realismo jurídico

1 El reconocimiento de la objeción de conciencia como derecho constitucional es la posición de la Corte Suprema de Justicia de Argentina. Cfr. "Portillo”, Fallos 312:496, (1989).

2 Cfr. Rodolfo Luis VIGo, "Derecho y moral en el Estado de derecho constitucional (Proyecciones teóricas: iuspositivismo, neoconstitucionalismo y realismo jurídico clásico)”, en Prudentia Iuris, 74 (2012), pp. 58-59.

3 Cfr. Rodolfo Luis Vigo, Las causas del derecho, Buenos Aires, Abeledo Perrot, 1983, p. 78; Carlos Ignacio MAssini CorreA, Filosofia del derecho, $2^{\text {a }}$ ed., Buenos Aires, Lexis Nexis, 2005, pp. 38-39; George Kalinowski, Concepto, fundamento y concreción del derecho, Buenos Aires, Abeledo Perrot, 1982 , p. 19.

4 Cfr. Javier Hervad, Lecciones propedéuticas de filosofía del derecho, Pamplona, Eunsa, 1992, p. 243.

5 Cfr. Michel Villey, Compendio de filosofia del derecho. Definiciones y fines del derecho, Pamplona, Eunsa, 1979, p. 87.

6 Andrés OlLERo, "Soy en realidad iusnaturalista”, en http://www.aafder.org/wp-content/uploads/2015/06/ Ollero-Soy-en-realidad-iusnaturalista.pdf, fecha de consulta: 15 de noviembre de 2015, p. 7. 
clásico, ${ }^{7}$ así como desde una visión constructivista como la de Rawls, Dworkin y Nino, ${ }^{8}$ las que se ven influenciadas por la filosofia moral kantiana, en tanto exaltan el principio de autonomía individual como aquel que justifica el ejercicio de la objeción de conciencia.

En este trabajo se delinearán, sin una pretensión de completa exhaustividad, algunos criterios para la interpretación del derecho a la objeción de conciencia. Para ello, se tendrán en cuenta los aportes de la filosofía jurídica, de la teoría de los derechos fundamentales y de la jurisprudencia de la Corte Suprema de Justicia de Argentina, de Estados Unidos, de la Corte Interamericana de Derechos Humanos (Corte IDH) y del Tribunal Europeo de Derechos Humanos. La referencia al Máximo Tribunal estadounidense se justifica por un doble orden de razones: en primer lugar, por cuanto en el caso "Portillo", el primero fallado por la mencionada Corte argentina, relativo a un supuesto de objeción de conciencia al servicio militar, se ha citado expresamente la doctrina de la Corte estadounidense, aplicando las pautas alli explicitadas. En segundo lugar, en virtud de que la jurisprudencia de esta última ha tratado en numerosos precedentes la problemática del derecho a la objeción de conciencia, el que se presentó como una forma de ejercicio del derecho a la libertad religiosa, tutelado por la primera enmienda de la Constitución de Estados Unidos. Así, tuvo la oportunidad de desarrollar criterios o test de constitucionalidad, los que, si bien no fueron uniformes a través del tiempo, podrían servir de guía al intérprete, complementándose con otros estándares, en la ardua tarea de delimitar la "esfera de funcionamiento razonable" del derecho a la objeción de conciencia. ${ }^{9}$

En cuanto a la Corte IDH, si bien no se ha pronunciado sobre el derecho a la objeción de conciencia, sí lo ha hecho con relación a otros derechos, resultando su doctrina analógicamente aplicable, tal como se desarrollará.

Con relación al Tribunal Europeo de Derechos Humanos, su jurisprudencia ha sido expresamente considerada y citada por la Corte IDH, por lo que su referencia resulta relevante a la hora de desarrollar los criterios de interpretación del derecho bajo estudio.

Del análisis de la jurisprudencia de los tribunales precitados pudo verse que un criterio posible para delinear la esfera de funcionamiento razonable de la objeción de conciencia lo constituye el principio de razonabilidad, denominado

7 Cfr. Javier Hervada, "Libertad de conciencia y error sobre la moralidad de una terapéutica", en Persona y Derecho 11 (1984), pp. 13-53; Jorge Guillermo Portella, La justificación iusnaturalista de la desobediencia civil y la objeción de conciencia, Buenos Aires, Educa, 2005.

8 Cfr. John Rawls, Teoría de la justicia, 2 ed., México, Fondo de Cultura Económica, trad. de M. D. González, 1997, pp. 404 y ss.; Ronald Dworkin, A Matter of principle, Oxford University Press, 1986, pp. 111 y ss. y Carlos Santiago Nino, Ética y derechos humanos. Un ensayo de fundamentación, 2

2589 ed., Buenos Aires, Astrea, 2005, pp. 229 y ss. La interpretación de los derechos fundamentales. Una alternativa a los conflictos de derechos, Buenos Aires, La Ley, 2000, p. 42. 
en el derecho continental europeo principio de proporcionalidad, lo que se expondrá a continuación.

\section{EL PRINCIPIO DE RAZONABILIDAD Y EL DERECHO}

\section{A LA OBJECIÓN DE CONCIENCIA}

El principio de razonabilidad constituye una herramienta frecuentemente utilizada por los tribunales para juzgar los casos donde se encuentran involucrados derechos fundamentales, pudiendo ser un medio que ayude al operador jurídico a determinar si la pretensión de formular objeción de conciencia en un supuesto determinado constituye el ejercicio de un derecho humano o, por el contrario, una pretensión irrazonable y antisocial.

Como es sabido, dicho principio se despliega bajo la forma de tres juicios: adecuación, necesidad y proporcionalidad en sentido estricto, los que son aplicados con diversidad de alcance e intensidad, según la naturaleza de los derechos afectados y los bienes públicos en juego. ${ }^{10}$

\subsection{El juicio de adecuación}

El subprincipio de adecuación exige valorar la idoneidad de la norma que reglamenta un derecho fundamental para alcanzar la finalidad perseguida mediante su dictado. Lo primero que se exige de una medida reguladora de derechos fundamentales es que tenga un fin legitimo y socialmente relevante, y que además sea adecuada para lograrlo. En otros términos, la idoneidad de la norma implica que los objetivos perseguidos sean "de carácter público; que su consecución sea posible, tanto fáctica como jurídicamente; que el fin al que se aspira y los medios elegidos sean constitucionalmente legitimos". ${ }^{11}$

Trasladando lo expuesto al caso del derecho a la objeción de conciencia, lo primero será indagar cuál es el fin que persigue la norma que impone el deber objetado y si esa finalidad es constitucionalmente admisible y socialmente relevante. Dicho de

10 Sobre el principio de proporcionalidad cfr. Javier BARNEs, "Introducción al principio de proporcionalidad en el derecho comparado y comunitario”, en Revista de Administración Pública, 135 (1994), pp. 495-522; Carlos BERnAl PuldDo, El principio de proporcionalidad y los derechos fundamentales. El principio de proporcionalidad como criterio para determinar el contenido de los derechos fundamentales vinculante para el legislador, Madrid, Centro de Estudios Políticos y constitucionales, 2003; Miguel CARBonELL (coord.), El principio de proporcionalidad en el Estado Constitucional, Bogotá, Universidad del Externado, 2007; Juan Cianciardo, El principio de razonabilidad. Del debido proceso sustantivo al moderno juicio de proporcionalidad, Buenos Aires, Ábaco de Rodolfo Depalma, 2004; Laura CleRICO, El examen de proporcionalidad en el derecho constitucional, Buenos Aires, Eudeba, 2009; Juan Carlos Gavara DE CARA, Derechos fundamentales y desarrollo legislativo. La garantía del contenido esencial de los derechos fundamentales en la Ley Fundamental de Bonn, Madrid, Centro de Estudios Constitucionales, 1994; Juan Francisco Linares, Razonabilidad de las leyes. El debido proceso como garantía innominada en la Constitución argentina, 2 ed., Buenos Aires, Astrea, 1970; Manuel Medina Guerrero, La vinculación negativa del legislador a los derechos fundamentales, Madrid, McGraw-Hill, 1996.

11 Javier BARNEs, "Introducción al principio de proporcionalidad...", op. cit., p. 503. 
otro modo, será preciso determinar si el deber está dirigido a la persecución de un bien público o a satisfacer el derecho de un tercero; como así también si el deber objetado resulta adecuado para alcanzar los objetivos pretendidos.

En tal sentido, Raz ensaya una clasificación de obligaciones objetables. Así, se refiere a tres tipos de deberes: a) impuestos a favor de la persona sometida al deber, a los que denomina paternalistas; b) impuestos en interés de otros individuos y c) impuestos en favor de un interés público. En el primer caso, considera que la exigencia de reconocer un derecho a la objeción de conciencia es más fuerte, pues el deber ha sido impuesto en interés del propio agente. ${ }^{12}$ En el segundo supuesto, entiende que el reclamo del objetor es menos convincente, pues el incumplimiento de tales deberes puede originar responsabilidades por daños e implicar medidas penales. ${ }^{13}$ Finalmente, cuando se trata de deberes para proteger el interés público, la contribución del objetor podría ser insignificante, por lo que produciría poca o ninguna diferencia discernible con respecto al bien protegido ${ }^{14}$.

El examen de adecuación de la obligación objetada fue realizado por la Corte Suprema de Estados Unidos en el caso Gonzales $v$. O Centro Espirita, ${ }^{15}$ en el que el Centro Espirita Beneficiente Uniao Do Vegetal (en adelante UDV) interpuso una demanda contra el Estado por violación de la primera enmienda y de la Religious Freedom Restoration Act (RFRA) de 1993, por cuanto no se le permitió importar de Brasil un tipo de té que se cultiva en dicho país, denominado ayahuasca, en inglés hoasca, el que era considerado como una droga alucinógena por el Gobierno de Estados Unidos. La UDV era una sociedad religiosa que como parte de sus prácticas efectuaba un uso religioso-ritual de la ayahuasca, y en el marco del proceso presentó como prueba estudios realizados por la Universidad de California acerca de los efectos de la ayahuasca, sobre un grupo de 15 consumidores rituales de esa infusión por más de 10 años, no habiéndose encontrado riesgo para su salud. El tribunal concluyó en que si bien la aplicación uniforme de la legislación antidroga y la observancia de las obligaciones internacionales asumidas por el Estado constituían un interés estatal imperioso, la RFRA exigia que el Gobierno demostrara la presencia de tales intereses en relación con la persona cuyo libre ejercicio de la religión es lesionado, según las concretas circunstancias del caso, ${ }^{16}$ lo que la Corte consideró que el Estado no había demostrado.

12 Cabe aclarar que los deberes impuestos en beneficio único del propio agente no son jurídicos, puesto que una nota de la justicia es la alteridad y nadie puede cometer injusticia consigo mismo (cfr. ARISTÓTELEs, Ética Nicomaquea, Libro V, XI). Sí, en cambio, podríamos encontrar deberes impuestos en beneficio del obligado y del interés público al mismo tiempo. Por ejemplo, la obligación de usar casco cuando se conduce una motocicleta está establecida en beneficio del obligado pero también del interés público, puesto que reducir el número de accidentados optimiza los recursos sanitarios que resultan escasos.

13 Raz omite considerar la posibilidad de obligaciones impuestas a favor de un tercero que puedan ser cumplidas por otro sujeto no objetor, evitando el daño que de su incumplimiento se derivaría. En otros términos, no se refiere a la aplicación del juicio de necesidad.

14 Cfr. Joseph RAz, La autoridad del derecho. Ensayos sobre derecho y moral, 2 ed., México, Universidad Autónoma de México, Imprenta Universitaria, 1985, pp. 346-350.

15546 U.S. 418 (2006).

16546 U.S. 418 , III A.

DÍKAION - ISSN 0120-8942 
Puede verse que el Estado alegó genéricamente un interés imperioso, pero no logró acreditar que, en las concretas circunstancias de la causa, ese interés se veía perjudicado o frustrado. La Corte efectuó lo que se denomina un "control intensivo" del juicio de adecuación de la medida impugnada — prohibición de la importación de ayahuasca-, la que debía estar estrictamente adaptada al logro de las finalidades pretendidas. Cabe aclarar, que el control intensivo de la idoneidad de la medida no admite generalizaciones o clasificaciones overinclusive, debiendo analizarse caso por caso si la medida adoptada es idónea para alcanzar la finalidad pretendida. La clasificación overinclusive tiene lugar cuando "el Gobierno omite clasificar con el resultado de que sus reglas o programas no distinguen entre personas que, para los propósitos de la igual protección, deberian ser consideradas como diferentemente situadas" 17.

\subsection{El juicio de necesidad}

La aplicación del juicio de necesidad supone determinar "si la medida adoptada por el legislador es la menos restringente de las normas iusfundamentales de entre las igualmente eficaces" 18 para alcanzar la finalidad perseguida.

El juicio de necesidad fue aplicado por la Corte Suprema de Estados Unidos en el caso Sherbert v. Verner, ${ }^{19}$ en el que la recurrente fue despedida de su trabajo por negarse a trabajar los sábados por razones de conciencia, pues formaba parte de la Iglesia Adventista del Séptimo Día, la que prohíbe trabajar los días sábados, basada en una interpretación de la Biblia. Debido a que no pudo conseguir otro trabajo, solicitó el beneficio de compensación por desempleo bajo la Ley de Compensación por Desempleo del estado de Carolina del Sur, el que le fue denegado por haberse constatado que la solicitante había rechazado empleos sin justas razones. El Estado había alegado en su defensa la posibilidad de que se completen solicitudes fraudulentas, invocando objeciones religiosas al trabajo sabático, lo que podría desfinanciar el fondo de compensación por desempleo y dificultar la planificación de empleadores que necesitan el trabajo sabático.

La Corte rechazó esta defensa, entre otros argumentos, mediante la aplicación del juicio de necesidad. En tal sentido, sostuvo que si la apelada llegara a demostrar que se dificulta el desarrollo del empleo o que se llenan muchas solicitudes falsas y ello amenaza el financiamiento del fondo, entonces será incumbencia de ella la demostración de que no existe otra alternativa en la forma de la regulación, para evitar esos abusos, sin que se infrinja la primera enmienda. ${ }^{20}$

Del mismo modo, el Máximo Tribunal estadounidense valoró la indispensabilidad de la medida en el caso Wisconsin v. Yoder $^{21}$. Alli, miembros de la religión amish

17 Laurence H. TRIBE, American constitutional law, 2 edition, Mineloa, New York, The Foundation Press, Inc., 1988, pp. 1438-1439.

18 Juan Cianciardo, El principio de razonabilidad..., op. cit., p. 79.

19374 U.S. 398 (1963).

20374 U.S. $398,408$.

21406 U.S. 205 (1972). 
se oponían a cumplir con la ley del estado de Wisconsin, la que los obligaba a mandar a sus hijos a la escuela hasta los 16 años de edad. Los padres, que se negaban a cumplir con dicha ley, consideraban que la escuela secundaria enseñaba valores radicalmente distintos a los valores de los amish, por lo que pretendian evitar que sus hijos fueran expuestos a esa influencia mundana que entraba en conflicto con sus creencias.

Del análisis del caso se infiere que el deber objetado presentaba una relación de adecuación con el fin buscado por el Estado, consistente en preparar a los ciudadanos para la efectiva e inteligente participación en el sistema político abierto, ser autónomos y autosuficientes participantes de la sociedad..$^{22}$ No obstante ello, la finalidad perseguida por el Estado también podía lograrse a través de otros medios alternativos de educación fuera del sistema formal - como los propuestos por los amish - que igualmente alcanzaban el objetivo perseguido mediante el sistema de educación formal obligatorio, preservaban el derecho de los niños a la educación y resguardaban el derecho a la libertad religiosa, que en el caso se manifestaba como el derecho a objetar por razones de conciencia.

Finalmente, en el caso Burwell v. Hobby Lobby Stores, Inc., de fecha 30 de junio de 2014, la Corte Suprema de Estados Unidos aplicó el juicio de necesidad prescrito en la Ley de Restauración de la Libertad Religiosa de 1993 (RFRA), considerando que el Departamento de Salud y Servicios Humanos de Estados Unidos (HHS), al exigir a tres sociedades por acciones cerradas que provean cobertura de salud para métodos anticonceptivos abortivos, violaba las sinceras creencias religiosas de los dueños de las compañias involucradas. En tal sentido, sostuvo que la HHS no había demostrado que carecía de otros medios para alcanzar sus propósitos sin imponer una limitación sustancial al ejercicio de la religión de los peticionantes en estos casos. ${ }^{23}$ Asimismo, agregó que "la manera más simple de alcanzar tal objetivo sería que el Estado asuma el costo de proveer esos cuatro anticonceptivos a aquellas mujeres que no pueden obtenerlos en virtud de que sus seguros de salud no los proveen por objeciones religiosas de sus empleadores". ${ }^{24}$

La Corte Suprema de Argentina también consideró la necesidad de la obligación objetada en el caso "Portillo", ${ }^{25}$ donde se planteó un supuesto de objeción de conciencia al cumplimiento del servicio militar. Para resolver el litigio, el precitado tribunal exigió evaluar "si es posible hallar alternativas que no eximan al sujeto obligado de sus deberes para con el Estado, pero tampoco violenten sus convicciones con grave riesgo de su autonomia”. ${ }^{26}$ Más adelante aclara esta exigencia, refiriéndose a la conveniencia de valorar “...la posibilidad de que los propósitos de

$22 \quad$ Ibid., 222.

23 Cfr. 573 U.S. (2014), V B. Para un análisis del caso cfr. María Marta Didier, Esteban José Ignacio RoMERo y Nicolás Francisco PARINI, "Objeción de conciencia: un fallo trascendente de la Corte Suprema de los Estados Unidos”, La Ley, 11 de noviembre de 2014, pp. 3-8.

$262 \quad 24$ Idem.

25 Fallos 312:496 (1989).

26 Ibid. 
defensa puedan ser satisfechos de una manera que evite el señalado conflicto de conciencia religiosa del peticionario". ${ }^{27}$

En contradicción con la doctrina sentada en "Portillo", el Máximo Tribunal argentino no aplicó el juicio de necesidad en el caso "F., A.L.”, al pronunciarse sobre el derecho a la objeción de conciencia del personal sanitario en los casos de abortos no punibles. En dicha oportunidad, si bien exhortó a las autoridades nacionales y provinciales a implementar un adecuado sistema que permita al personal sanitario ejercer su derecho a la objeción de conciencia, sostuvo que la objeción debía ser manifestada en el momento de la implementación del protocolo o al inicio de las actividades en el establecimiento de salud correspondiente. Ello no contempla la posibilidad de que un profesional formule objeción de conciencia luego de implementado el protocolo o de ingresar al establecimiento, por haber modificado su convicción ética o religiosa con relación a la práctica del aborto. En concreto, el fallo debió haber considerado una medida menos restrictiva del derecho a la objeción de conciencia, por cuanto, como acertadamente se ha señalado, la conciencia no es estática, debiendo protegerse la que se expresa aquí y ahora, aún cuando resulte contradictoria con prácticas anteriores. ${ }^{28}$

El Tribunal Europeo de Derechos Humanos, en el caso Bayoyan c. Armenia, del 7 de julio de 2011, sobre objeción al servicio militar, se refirió al juicio de necesidad cuando sostuvo que una restricción de la libertad de conciencia no puede considerarse necesaria en una sociedad democrática, cuando existen otras maneras de conciliar los respectivos intereses contrapuestos del legislador y del objetor. ${ }^{29}$

En el sentido señalado por la jurisprudencia precitada, se ha sostenido que:

...dada la importancia de este derecho humano que toca la interioridad de las personas, sus creencias y convicciones más profundas, la restricción estatal debe ser la excepción y solo cuando no exista otro medio similar para satisfacer los intereses sociales. De haberlos, corresponde su empleo alternativo a fin de resguardar la conciencia personal. Así pues, el examen de cuán indispensable es el cumplimiento del fin social por el medio establecido debe ser estricto cuando ello obstruya las convicciones morales o religiosas de las personas. ${ }^{30}$

27 Idem, considerando 13.

28 Cfr. Marina Gascón Abellán, Obediencia al derecho y objeción de conciencia, Madrid, Centro de Estudios Constitucionales, 1990, p. 324.

29 Cabe aclarar que el Tribunal Europeo de Derechos Humanos no ha sido coherente con esta doctrina, pues en otros casos ha omitido la aplicación del juicio de necesidad, al no considerar la existencia de otras medidas alternativas, a fin de conciliar el derecho a la objeción de conciencia y los objetivos perseguidos por el legislador. Al respecto, cfr. Eweida y otros c. Reino Unido, demandas 48420/10, 59842/10, 51671/10 y 36516/10, del Tribunal Europeo de Derechos Humanos y Rafael Navarro Valls y Javier Martinez Torrón, Conflictos entre conciencia y ley. Las objeciones de conciencia, 2 ed., Madrid, Iustel, 2012, p. 52.

30 María Angélica Gelli, Constitución de la Nación Argentina. Comentada y concordada, 3 ed., Buenos Aires, La Ley, 2005, p. 137. 
Resulta fundamental que tanto el legislador como los tribunales, al juzgar las contiendas que se les presenten sobre objeción de conciencia, apliquen el juicio de necesidad. Para ello deberán preguntarse si el deber objetado que persigue una finalidad de bien público o constituye la contraprestación para la salvaguarda del derecho de un tercero, puede ser cumplido por otra persona o mediante una prestación alternativa que resulte igualmente idónea para alcanzar el objetivo perseguido -educación no formal, en el caso de los amish, prestación por parte del Estado en el caso Hobby Lobby, y servicio de conscripción sin empleo de armas, en el caso Portillo-.

\subsection{El juicio de proporcionalidad en sentido estricto}

Una vez superados los juicios de adecuación y de necesidad, la máxima de razonabilidad exige valorar la proporcionalidad en sentido estricto de la medida sometida a juzgamiento, lo que supone ponderar "si los medios elegidos y el sacrificio que generan sobre los ciudadanos (costes) compensan o guardan una relación razonable o proporcional con los beneficios que de su aplicación resultarian para el interés general". ${ }^{31}$

El juicio de proporcionalidad en sentido estricto se vincula con lo que Alexy, tomando como base la jurisprudencia del Tribunal Constitucional Alemán, denominó ley de la ponderación, conforme a la cual, "cuanto mayor sea el grado de no satisfacción o de afectación de un principio, tanto mayor tiene que ser la importancia de la satisfacción del otro". ${ }^{32}$

Desde la doctrina se han señalado criterios para regular la objeción de conciencia que se traducen en la aplicación del juicio de proporcionalidad en sentido estricto. Así, por ejemplo Raz, se refiere a aquellas obligaciones jurídicas establecidas en beneficio del interés público cuya satisfacción se compone de muy pequeñas contribuciones individuales, de modo tal que el incumplimiento de la obligación por parte del objetor, si bien hace disminuir la protección del bien público, no lo frustra de ningún modo, por lo que el daño producido no compensa el sacrificio de la libertad de conciencia. ${ }^{33}$

También se ha destacado la importancia de atender a la esencialidad del bien o valor protegido por el deber jurídico incumplido y a la irreversibilidad de la lesión que tal incumplimiento produce. ${ }^{34}$ La irreversibilidad del daño producido se refiere a la imposibilidad de reparación material del daño con el acto de la objeción, pudiéndose subsanar con la sustitución del sujeto pasivo de la obligación. ${ }^{35}$

31 Javier BARNEs, “Introducción al principio de proporcionalidad”, op. cit., p. 507.

32 Robert Alexy, Teoría de los derechos fundamentales, Madrid, Centro de Estudios Constitucionales, trad. de Ernesto Garzón Valdés, 1993, p. 161.

33 Cfr. Joseph RAz, La autoridad del derecho, op. cit., pp. 349-350.

34 Cfr. Ramón SoRiano, "La objeción de conciencia: significado, fundamentos jurídicos y positivización en el ordenamiento jurídico español”, en Revista de Estudios Politicos, 58 (1987), pp. 81 y ss. Ibid. 
El subprincipio de proporcionalidad en sentido estricto fue aplicado por la Corte Suprema de Estados Unidos, entre otros, en los casos Sherbert v. Verner, Wisconsin v. Yoder, Gonzales v. O Centro Espirita y Burwell v. Hobby Lobby Stores, Inc. referidos en los epígrafes 1.1. y 1.2., exigiéndose la concurrencia de un interés estatal imperioso a los fines de justificar el rechazo de las objeciones de conciencia planteadas en el marco del derecho a la libertad religiosa.

La Ley Federal de Restauración de la Libertad Religiosa, vigente en Estados Unidos, requiere aplicar tanto el juicio de proporcionalidad en sentido estricto como el de necesidad, al establecer en la Sección 3 que el Gobierno no debe imponer una carga sustancial al ejercicio de la religión de una persona, aún cuando esa carga resultare de una norma de aplicabilidad general, excepto que el Gobierno demuestre que mediante dicha imposición se persigue un interés gubernamental imperioso y es el medio menos restrictivo para alcanzar el referido interés.

La Corte Suprema de Argentina también se refirió al juicio de proporcionalidad en sentido estricto en el caso "Portillo", ${ }^{36}$ en el que consideró que el incumplimiento de la obligación de prestar el servicio militar "no conlleva un peligro grave o inminente a los intereses protegidos por el Estado toda vez que el servicio que se exige debe ser cumplido en tiempos de paz y no requiere, necesariamente, limitar la libertad de conciencia”. ${ }^{37}$

Lo expuesto en el párrafo precedente implica que el tribunal, o la autoridad administrativa competente para el reconocimiento de la objeción de conciencia formulada, deberá valorar o sopesar la importancia del objetivo perseguido mediante el cumplimiento de la obligación jurídica y el grado de interferencia o peligro que provoca el incumplimiento. Si el reconocimiento del derecho invocado no conlleva peligro grave o inminente, y tampoco atenta contra el derecho fundamental de un tercero o frustra los fines de bien público en pos de los cuales la obligación ha sido impuesta, resultaría desproporcionado exigir su cumplimiento, denegando el ejercicio de la objeción de conciencia formulada.

\subsection{El juicio de afectación o alteración del contenido esencial}

Ahora bien, la aplicación del juicio de proporcionalidad en sentido estricto, como mero balance entre costos y beneficios, conduce a un análisis utilitarista en el juzgamiento de la reglamentación de los derechos fundamentales o en la actividad de interpretación y determinación del contenido de tales derechos. Ello, por cuanto obliga a postergar un derecho fundamental en pos de otro derecho o de una finalidad de bien público, relativizando los derechos, sometiéndolos a las exigencias derivadas de la utilidad o el interés general y transformándolos en frágiles "edictos de tolerancia revocables". ${ }^{38}$

38 Robert SpaEmann, "Sobre el concepto de dignidad humana", en Carlos Ignacio MASsini y Pedro Serna (eds.), El derecho a la vida, Pamplona, Eunsa, 1998, p. 82. 
A los fines de no reducir el juicio de proporcionalidad en sentido estricto a un cálculo utilitarista, Cianciardo ha sostenido que la proporcionalidad stricto sensu de una medida presupone dos cosas: “a) que la medida no altera el contenido del derecho fundamental involucrado; y b) que la medida no alteradora introduce precisiones tolerables de la norma iusfundamental, teniendo en cuenta la importancia del fin perseguido". ${ }^{39}$ De este modo, es preciso "comprobar que no se ha afectado el contenido del derecho. A partir de ahí se efectuará el balanceo de ventajas y cargas". ${ }^{40}$

En el derecho argentino, la garantía de la inalterabilidad de los derechos fundamentales constituye una exigencia de razonabilidad de la regulación normativa de tales derechos, prescrita por el artículo 28 de la CN, según el cual "los principios, garantías y derechos reconocidos en los anteriores artículos, no podrán ser alterados por las leyes que reglamenten su ejercicio". De alli, el criterio sustentado por la Corte Suprema argentina para quien "cuando la sustancia de un derecho constitucional se ve aniquilada por las normas que lo reglamentan, ni las circunstancias de emergencia son atendibles, incluso en el terreno del derecho patrimonial". ${ }^{41}$ Ello significa que, aún existiendo un interés sustancial para el Estado, no sería razonable aniquilar o violentar el derecho constitucional en juego, resultando insuficiente un mero balance entre ventajas y desventajas para juzgar la proporcionalidad de la medida considerada.

Para la determinación del contenido esencial del derecho a la objeción de conciencia, considero que no resulta conveniente entenderlo desde la sola autonomía moral, pues en tal supuesto, se presentarán conflictos imposibles de solucionar racionalmente, en tanto la autonomía del objetor se enfrentará a la autonomía del tercero en beneficio del cual el deber objetado fue establecido, sin resultando factible determinar hasta dónde llega la autonomía de uno y de otro ante la ausencia de criterios materiales.

Una de las pautas - sin excluir otras posibles - que resultarian útiles para determinar el contenido esencial del derecho bajo análisis, podría ser la de atender a los bienes humanos que protege el derecho a la objeción de conciencia. Ello, por cuanto la materia de los derechos humanos, o sea, su contenido, se corresponde con los bienes humanos básicos, conforme a lo sostenido en este aspecto por John Finnis, para quien el proceso de especificación y demarcación de los derechos necesita de "una concepción del bien humano, de la realización individual, según una forma (o conjunto de formas) de vida en común que promueva en lugar de obstaculizar tal realización”. ${ }^{42}$ Siguiendo en este punto a Finnis, se ha señalado

39 Juan CiAnCIARDo, El principio de razonabilidad, op. cit., p. 99.

40 Idem.

41 Considerando 12 del voto de los ministros Fayt, Petracchi y Boggiano en "Dessy”, Fallos 318:1894 (1995).

42 John Finnis, Ley natural y derechos naturales, Buenos Aires, Abeledo Perrot, trad. de Cristóbal Orrego Sánchez, 2000, pp. 247-248. 
que "cada derecho humano se ordena, por tanto, a la realización de uno o varios bienes humanos básicos y recibe a su vez de estos su justificación objetiva” ${ }^{43}$

Para el filósofo australiano, los bienes humanos básicos constituyen "una serie de principios prácticos básicos que muestran las formas de realización humana plena como bienes que se han de perseguir y realizar, y que son usados de una manera u otra por cualquiera que reflexiona acerca de qué hacer, no importa cuán erróneas sean sus conclusiones". ${ }^{44}$ Entiendo que, en el caso de la objeción de conciencia, tales bienes humanos están constituidos por lo que Finnis ha denominado la "razonabilidad práctica" y la "religión". ${ }^{45}$

La razonabilidad práctica es concebida como:

el bien básico de ser capaz de hacer que la propia inteligencia se aplique eficazmente (en el razonamiento práctico que da por resultado una acción) a los problemas de elegir las acciones y el estilo de vida de cada uno y de formar el propio carácter. Dicho de modo negativo, esto implica que uno tiene una medida de libertad efectiva; de modo positivo, implica que uno busca introducir un orden inteligente y razonable en las propias acciones y hábitos y actitudes prácticas. ${ }^{46}$

La razonabilidad práctica plantea determinadas exigencias que se refieren a lo que uno debe hacer, o pensar, o ser, si ha de participar en el valor básico de la razonabilidad práctica; cada una de ellas es fundamental, inderivada e irreductible. ${ }^{47}$ Entre las nueve exigencias está la que consiste en "seguir la propia conciencia", a la que Finnis considera un aspecto particular de la séptima exigencia (ningún bien básico puede ser atacado directamente en ningún acto) o también un resumen de todas las exigencias. El seguir la propia conciencia supone que uno no debe hacer lo que juzga o piensa que no debiera hacerse, o sea, debe actuar conforme a su conciencia. ${ }^{48}$

A la luz de lo anterior, cabría afirmar que si el derecho a la objeción de conciencia tiene por objeto el bien humano de la razonabilidad práctica, no podrá considerarse que se encuentra dentro del ámbito protegido por tal derecho la realización de una conducta que contrarie ciertas exigencias que aquella plantea, tales como

43 Carlos Ignacio MAssinI, "El derecho a la vida en la sistemática de los derechos humanos", en El derecho a la vida, op. cit., p. 192.

44 John Finnis, Ley natural y derechos naturales, op. cit., p. 58. Cfr. también John Finnis y Germain Grisez, "The Basic Principles of Natural Law: A Reply to Ralph MacInerny", en American Journal of Jurisprudence, 26 (1981), pp. 21-31; Joseph BoyLe, Germain Grisez y John Finnis, "Practical Principles, Moral Truth, and Ultimate Ends”, en Scholarly Works, 846 (1987), pp. 99-151, en http://scholarship.law.nd.edu/law_faculty_scholarship/846, fecha de consulta 7 de noviembre 2015; Carlos MASSINI CORREAS, "La nueva escuela anglosajona del derecho natural", en Las razones del derecho natural, Renato Rabbi Baldi (coord.), Buenos Aires, Abaco, 1998, pp. 255-277; Marina DANDoIs, "Los bienes humanos básicos y la fundamentación del derecho. Un estudio de la propuesta de John Finnis”, en Dikaion, 23-1 (2014), pp. 37-53.

45 Cfr. John Finnis, Ley natural y derechos naturales, op. cit., pp. 117-121.

46 Ibid., p. 119.

47 Ibid., p. 133.

48 Ibid., p. 154. 
no atentar directamente contra un bien humano básico y promover el bien común de las propias comunidades. ${ }^{49}$

Desde esta perspectiva, no formarian parte de la denominada "esfera material" del derecho a la objeción de conciencia ${ }^{50}$ aquellas acciones por las que el objetor daña o impide la realización o participación en una forma básica de bien humano, como sería el caso de quien presta su asistencia al suicidio y justifica su acción en imperativos de conciencia para eximirse de la sanción penal; o las prácticas de infibulación o escisión femenina, propias de ciertas comunidades islámicas, respaldadas en una determinada interpretación del Corán. Debido a que mediante dichas conductas se estaría atentando directamente contra el bien humano de la vida de quien solicita su asistencia para el suicidio, y contra el bien humano de la salud e integridad fisica de la mujer sobre la que se realiza dicha práctica, no cabria considerarla como un ejercicio razonable de la objeción de conciencia, encontrándose fuera del ámbito de protección del derecho bajo análisis. ${ }^{51}$

Esta vinculación entre el derecho a la objeción de conciencia y el bien humano de la razonabilidad práctica, también puede verse en las exigencias que la misma jurisprudencia señala como condición para el ejercicio del derecho. Así, según la jurisprudencia de Estrasburgo, para que una objeción de conciencia pueda estimarse digna de ser tomada en consideración, se deberá tener en cuenta que la convicción o creencia proceda de un sistema de pensamiento suficientemente estructurado, coherente y sincero. ${ }^{52}$ En el mismo sentido, la Cámara de los Lores, en el caso Williamson, ${ }^{53}$ sostuvo que:

...una creencia, religiosa o no, para poder ser considerada como tal, ha de cumplir modestos requisitos mínimos, que se encuentran implícitos en el art. 9 CEDH. En particular, debe ser coherente con unos estándares elementales de dignidad humana, referirse a problemas fundamentales y no a cuestiones triviales y revestir un cierto grado de seriedad e importancia. Además, ha de resultar inteligible, aunque

49 Ibid., pp. 148-154. Según Finnis "el bien común es el conjunto de condiciones que capacita a los miembros de una comunidad para alcanzar por sí mismos objetivos razonables, o para realizar razonablemente por sí mismos el valor (o los valores), por los cuales ellos tienen razón para colaborar mutuamente [...] en una comunidad [...]. El bien común en este sentido es un significado frecuente o al menos justificado de las frases el bienestar general o el interés público" (Ley natural y derechos naturales, op. cit., p. 184.

50 La terminologia "esfera material" es propuesta por Fernando M. Toller, "Los derechos in concert. Metodologias para tomar decisiones armonizadoras en casos entre derechos y bienes constitucionales", en Juan Cianciardo (coord.), Constitución, neoconstitucionalismo y derechos, México, Porrúa, 2012, pp. 137-144.

51 Adviértase que, para Finnis, el carácter inviolable de los derechos humanos básicos se sustenta en la exigencia de la razonabilidad práctica conforme a la cual no se debe realizar ningún acto que de suyo no hace más que dañar o impedir la realización o participación en una o más de las formas básicas de bien humano. (Cfr. John Finnis, Ley natural y derechos naturales, op. cit., pp. 148, 151 y 251-253).

52 Cfr. TEDH, Campbell y Cosans c. Reino Unido, 25 de febrero de 1982.

$26853 \mathrm{El}$ caso, rotulado $R v$. Secretary of State for Education and Employment and others ex parte Williamson (2005) UKHL 15, se refería a unos padres que reclamaban que sus hijos pudieran ser sancionados con castigos físicos en el colegio - lo que resulta ilegal para el derecho inglés-, pues alegaban que ello respondía a sus convicciones morales. 
esto no haya de interpretarse como una rígida exigencia de exposición sistemática o, aún menos, de justificación racional, pues las creencias de suyo implican elecciones que van más allá de lo racionalmente demostrable, y más todavía en el caso de las religiones, que con frecuencia se basan en una realidad sobrenatural. ${ }^{54}$

En sentido similar, Vigo ha señalado que para la procedencia de la objeción de conciencia, entre otras cuestiones, debe considerarse "la racionalidad o justificación de las mismas convicciones intimas aducidas, lo cual no implica juzgar desde una determinada moral, sino advertir que hay un limite racional en el que caben distintas morales o proyectos de vida". ${ }^{55}$ Este limite racional podría plasmarse en dos exigencias de la razonabilidad práctica, las que consisten, tal como se expuso, en no atentar directamente contra un bien humano básico y promover el bien común de las propias comunidades, siendo preciso aclarar que dentro de tales exigencias caben diversos planes de vida. ${ }^{56}$

Lo sostenido no significa que el tribunal u órgano administrativo frente al cual se invoca el derecho a la objeción de conciencia, para eximirse del cumplimiento de un deber o de la sanción que impone el ordenamiento jurídico, deba juzgar si las creencias o convicciones del objetor resultan "correctas o verdaderas". Ello no corresponde, sino más bien, lo que debe considerar, es la sinceridad del objetor, la coherencia, seriedad y racionalidad de la creencia, entendiendo esto último en el sentido de la razonabilidad práctica, la que impone, reitero, considerar las consecuencias de la conducta del objetor en orden a la realización del bien común y los derechos humanos de los terceros.

\section{LA CARGA DE LA JUSTIFICACIÓN}

Otra cuestión que presenta el ejercicio del derecho a la objeción de conciencia se vincula con el interrogante acerca de quién corre con la carga de la justificación, en los casos donde el mencionado derecho sea invocado y la parte contra quien se pretenda hacer valer se oponga a su procedencia. Por carga de la justificación ha de entenderse carga de la argumentación y de la prueba, o sea, exposición de las razones que dan sustento a la oposición, como así también acreditación de los hechos que integran las razones invocadas.

Considero que el objetor debe exponer las razones éticas o religiosas por las que se niega al cumplimiento del deber jurídico, las que, como se especificó, deben responder a un sistema de pensamiento coherente - pues la coherencia es un requisito minimo formal de racionalidad-, serio, inteligible y referirse a cuestiones fundamentales o de suficiente importancia. Pero más allá de estos requisitos, otra

54 Citado por Rafael Navarro Valls y Javier Martinez Torrón, Conflictos entre conciencia y ley, op. cit., pp. 74-75.

55 Rodolfo Luis VIGo, "Derecho a la objeción de conciencia: implicancias y consecuencias”, El derecho. Diario de doctrina y jurisprudencia, 28 de agosto de 2015, p. 2.

56 Cfr. John Finnis, Ley natural y derechos naturales, op. cit., pp. 123-125, 134-137 y Robert GEoRGE, Making man moral, New York, Oxford University Press, 1993, pp. 39-40. 
carga no debe ser impuesta sobre el objetor. Será al Estado o a quien se oponga a la procedencia de la objeción de conciencia, a quien corresponde acreditar: a) cuál es la finalidad legitima perseguida mediante la obligación objetada, b) la concurrencia de una relación de adecuación estricta entre la obligación objetada y dicha finalidad, c) la inexistencia de otros medios alternativos para alcanzarla, d) que dicha finalidad se identifica con un interés sustancial o imperioso y e) la inalterabilidad del contenido esencial del derecho a la objeción de conciencia. Todo estos extremos no deberán ser invocados de modo genérico, sino probados en las concretas circunstancias del caso.

En tal sentido, aunque vinculado estrictamente a la libertad religiosa, pero también aplicable a las objeciones de conciencia por razón de la religión, la Ley de Restauración de la Libertad Religiosa (Religious Freedom Restoration Act, de 1993), vigente en Estados Unidos, impone la carga de la justificación sobre el Estado que pretende limitar sustancialmente el ejercicio de la religión. Los fallos de la Corte Suprema de Estados Unidos ya referidos, también han adoptado idéntica postura, antes de la sanción de dicha ley, por considerar que debía aplicarse un escrutinio estricto (Sherbert v. Verner y Wisconsin v. Yoder) y luego de su sanción, por aplicación de las exigencias legales (Gonzales v. O Centro Espirita y Burwell v. Hobby Lobby Sores, Inc. ${ }^{57}$.

En consonancia con la jurisprudencia precitada, un importante sector de la doctrina ha sostenido que la carga de la justificación pesa sobre la parte que pretende denegar el ejercicio de la objeción de conciencia. ${ }^{58}$

Estimo acertada la posición referida por diversas razones: en primer lugar, porque la objeción de conciencia constituye una forma de ejercicio de las libertades de conciencia y religión, las que revisten la condición de derechos humanos y a la vez constitucionales o fundamentales. En segundo lugar, porque los estudios demuestran que los países que protegen fuertemente la libertad religiosa y de conciencia son más seguros y estables que aquellos que no lo hacen, y las naciones que vulneran dichas libertades constituyen un terreno fértil para la guerra y la pobreza, el terrorismo y los movimientos extremistas. ${ }^{59}$ En efecto, la objeción de conciencia se convierte en el más firme obstáculo para cualquier modalidad de tiranía, en la más segura defensa de la libertad y de la dignidad del ser humano, ${ }^{60}$

57 Acerca de la evolución jurisprudencial del derecho a la libertad religiosa en Estados Unidos cfr. José Ignacio RUBIo LóPEz, "La última aplicación de la doctrina norteamericana del Strict Scrutiny en el derecho de libertad religiosa: González V. O Centro Espirita”, en Ius Canonicum, XLVI, 92 (2006), pp. 581-622.

58 Cfr. Marina GASCÓn ABELLÁN, Obediencia al derecho y objeción de conciencia, op. cit., p. 221 y Javier MARTínez TorRón, "Una metamorfosis incompleta. La evolución del derecho español hacia la libertad de conciencia en la jurisprudencia constitucional”, en Persona y Derecho, 45 (2001), p. 259. En el mismo sentido, cfr. Rafael Navarro Valls y Javier Martinez Torrón, Conflictos entre conciencia y ley, op. cit., p. 69.

59 Cfr. Roberto P. George, "Those of us who care about religious freedom have a job to do", Vital Speeches of the Day 80 (febrero 2014), p. 36.

60 Cfr. Luis Fernando Velázguez Córdoba y Ramón CóRdoba Palacio, "Objeción de conciencia y la antropología filosófica”, Persona y Bioética 14, 2 (2010), p. 175. 
constituyendo su reconocimiento como derecho fundamental, "la piedra de toque de la madurez democrática de un ordenamiento jurídico". ${ }^{61}$

En tercer lugar, por cuanto concurren razones de orden práctico, vinculadas a que es el Estado o quien se oponga a la objeción formulada, los que tienen el conocimiento y los medios para acreditar los extremos indicados precedentemente.

\section{El TEST DE CONSTITUCiONALIDAD APLiCABLE}

En el presente apartado se sostendrá que en el ordenamiento constitucional argentino, conforme a criterios sentados por la Corte Suprema de Argentina y por la Corte Interamericana de Derechos Humanos IDH, corresponde la aplicación de un examen intensivo de razonabilidad o escrutinio estricto, en aquellos supuestos en los que se plantea un conflicto que involucre el ejercicio de la objeción de conciencia. Ello se justifica en las siguientes razones.

La objeción de conciencia constituye un derecho fundamental o constitucional, derivado de la libertad de conciencia y religión, tal como lo ha reconocido la Corte Suprema de Argentina en el ya citado fallo "Portillo". Según lo ha sostenido dicho Tribunal en el precedente mencionado, el fundamento positivo del derecho bajo análisis se encuentra en los artículos 14, 16 y 19 de la Constitución Nacional. En el artículo 14, en tanto consagra la libertad de conciencia y de cultos; en el artículo 19, por cuanto contiene el principio de autonomía y en el artículo 16, referido a la igualdad ante la ley y en el que se sustenta la obligación de protección de las minorías. ${ }^{62}$

Asimismo, en el caso "Bahamondez", los jueces Cavagna Martinez y Boggiano destacaron la relación existente entre el principio de no discriminación y el derecho a la objeción de conciencia. En tal sentido, sostuvieron que:

...la convivencia pacífica y tolerante también impone el respeto de los valores religiosos del objetor de conciencia, en las condiciones enunciadas, aunque la sociedad no los asuma mayoritariamente. De lo contrario, bajo el pretexto de la tutela de un orden público erróneamente concebido, podría violentarse la conciencia de ciertas personas que sufrirían una arbitraria discriminación por parte de la mayoría con perjuicio para el saludable pluralismo de un Estado democrático. ${ }^{63}$

Finalmente, en el precedente "Asociación Testigos de Jehová”, la jueza Highton sostuvo que obligar a los docentes que formaban parte de los Testigos de Jehová a honrar los símbolos patrios resultaba incompatible con la prohibición de discri-

61 Andrés Ollero, "Soy en realidad iusnaturalista", op. cit., p. 6.

62 Cfr. Fallos 312:496, considerando 10.

63 Fallos 316: 479 (1993), considerando 18 del voto de los jueces Antonio Boggiano y Mariano Cavagna Martínez. 
minar por razones religiosas consagrada en el artículo 18 del Pacto Internacional de Derechos Civiles y Políticos, de jerarquía constitucional. ${ }^{64}$

La vinculación entre los derechos a la igualdad y a la objeción de conciencia señalada por el Máximo Tribunal argentino resulta acertada, puesto que existen estrechas relaciones entre ambos derechos fundamentales. Por una parte, cabe afirmar que todos los seres humanos son titulares por igual de los derechos a la libertad de conciencia y de religión, en los que se fundamenta el derecho a la objeción de conciencia; y por la otra, nadie debe ser discriminado con sustento en su religión, pues de tal modo se violaría el derecho a la igualdad (cfr. artículo 1 de la Convención Americana sobre Derechos Humanos y artículo 2 de la Declaración Universal de Derechos Humanos y del Pacto Internacional de Derechos Civiles y Políticos).

Sin embargo, como bien se ha señalado, la prohibición de discriminación no "debe entenderse como uniformidad, sino como una proporcionalidad cualitativa, lo que supone no la existencia de un tratamiento legal igual, con abstracción de cualquier elemento diferenciador de relevancia jurídica, sino en función de las circunstancias que concurran en cada supuesto concreto en relación con el cual se invoca" ${ }^{65}$

En el mismo sentido, para la jurisprudencia constitucional argentina, estadounidense e italiana, el principio de igualdad no solo implica que el creador de la norma jurídica general no pueda introducir diferenciaciones irrazonables, sino que también exige que situaciones desiguales no sean tratadas de modo igual por el legislador o el poder administrador, estando obligado en tales casos a efectuar un tratamiento desigual. ${ }^{66}$ Asimismo, el Tribunal Europeo de Derechos Humanos ha resuelto que resulta discriminatorio el trato idéntico de dos situaciones que son sustancialmente diferentes, ${ }^{67}$ ampliando de tal modo el contenido del principio de no discriminación. Con especial referencia a la libertad religiosa, sostuvo que el ejercicio de la misma podría constituir un importante factor de desigualdad real y reclamar, por tanto, que el legislador acepte excepciones a la norma aplicable en la generalidad de los casos.

La discriminación por razón de la religión podría darse cuando las normas o prácticas obstaculizan su ejercicio, denegando la pretensión de objetar por razón

64 Cfr. Fallos 326:2966 (2005), voto de la jueza Highton de Nolasco, considerando 16.

65 José María Contreras Mazarío, "Libertad de conciencia y convicción en el sistema constitucional español”, en Revista CIDOB D`Afers Internationals 77, p. 45; cfr. STC del 2 de julio de 1981, fundamento jurídico 3 y STC del 10 de julio de 1981, fundamento jurídico 4 .

66 Para la Corte Suprema argentina, el principio de igualdad resultaría vulnerado "si se contemplare en forma idéntica casos que entre sí son diferentes” (Fallos 327:4495[2004]). Según la Corte Suprema de Estados Unidos, a veces la mayor discriminación puede consistir en tratar cosas que son diferentes como si fueran exactamente iguales (Jennes vs. Fortson, 403 U.S. 431, [1971]). La Corte Constitucional italiana ha sostenido que "el principio de igualdad también se viola si situaciones desiguales reciben un trato normativamente igual” (José SuAY RINcón, El principio de igualdad en la justicia constitucional, Madrid, Instituto de Estudios de Administración Local, 1985, p. 52). El autor también menciona las siguientes sentencias: 99/65; 22 y 81/66; 119/69; 14/71; 93/72; 36/73 y 119/76.

67 Caso Thlimmenos contra Grecia, del 6 de abril de 2000. Un comentario de dicha sentencia puede verse en Rafael Navarro Valls y Javier Martínez Torrón, Conflictos entre conciencia y ley, op. cit., p. 101. 
de las convicciones religiosas, sin que exista una justificación objetiva y razonable. En tal supuesto, la persona a quien se le deniega el derecho a objetar estaría siendo discriminada por adherir a determinada religión, viéndose obligada a cumplir con prestaciones o conductas que contrarian sus convicciones. Se la trataria formalmente igual al resto de los sujetos a quienes está dirigida la obligación constitucional, legal, reglamentaria o convencional, pero se violentaría la igualdad proporcional, conforme a la cual la distribución de obligaciones o cargas dentro del grupo social no debe responder a una igualdad aritmética o a una simetría abstracta, sino a una igualdad geométrica, es decir, proporcionada a las personas y circunstancias. ${ }^{68}$

Con fundamento en lo expuesto, puede concluirse que cuando se deniega injustificadamente el ejercicio del derecho a la objeción de conciencia por razones religiosas, no solo se está violentando el mencionado derecho fundamental, sino que también se vulnera el derecho a no ser discriminado por razón de la religión. Ello, porque cuando el Estado impone el cumplimiento de una obligación que contraría las convicciones religiosas de una persona o grupos de personas, si bien les dispensa un trato igualitario con relación al resto de los sujetos destinatarios de la obligación, dicho trato es discriminatorio por haberse omitido diferenciar, atendiendo a la posición de desigualdad en que se encuentran los sujetos sobre los que se imponen las obligaciones objetadas. En otros términos, se trataria de una hipótesis de discriminación por indiferenciación.

En el supuesto referido, considero que debe aplicarse un examen intensivo de razonabilidad o un escrutinio estricto, por estar en juego un criterio de discriminación expresamente prohibido por los tratados internacionales de derechos humanos, cual es la religión, criterio que, conforme a la jurisprudencia del Máximo Tribunal argentino, se presume inconstitucional y da lugar a la aplicación de un examen más riguroso de razonabilidad. ${ }^{69}$

Dicho examen intensivo de razonabilidad también debe ser aplicado con sustento en la interpretación que la Comisión Interamericana de Derechos Humanos (CIDH) y la Corte Interamericana de Derechos Humanos (Corte IDH) han conferido a las normas que integran la Convención Americana sobre Derechos Humanos. ${ }^{70}$ En tal sentido, y en coincidencia con lo resuelto por la Corte Suprema de Argentina,

68 Sobre las distinciones entre igualdad aritmética e igualdad geométrica cfr. ARISTóteles, Ética Nicomaquea, Libro V; Javier HervadA, Lecciones propedéuticas, op. cit., pp. 221-224; Michel Villey, Compendio de filosofía del derecho, op. cit., pp. 90-95; John Finnis, Ley natural y derechos naturales, op. cit., pp. 214-221.

69 Cfr. "Hooft”, Fallos 327:5118 (2004); “Gottschau”, Fallos 329:2986 (2006); “Mantecón Valdés”, Fallos 331:1715 (2008) y "Partido Nuevo Triunfo”, Fallos 332: 433 (2009). Asimismo, ver María Marta DIDIER, El principio de igualdad en las normas jurídicas. Estudio de la doctrina de la Corte Suprema de Argentina y su vinculación con los estándares de constitucionalidad de la jurisprudencia de la Corte Suprema de los Estados Unidos, Buenos Aires, Marcial Pons, 2012, pp. 243-332.

70 Cabe aclarar que la Corte IDH no se ha pronunciado sobre el derecho a la objeción de conciencia y la CIDH sostuvo que la objeción de conciencia era un derecho emanado del artículo 12 solo en los Estados donde fue reconocido en su legislación interna (Cfr. CIDH, caso 12.219. Cristián Daniel Sahli Vera y otros (Chile), informe 43/05 (10/04/2005). Debido a que la objeción de conciencia es reconocida como derecho constitucional en la Argentina, tanto a nivel legislativo como jurispru- 
la Comisión ha sostenido que: "las distinciones basadas en los factores mencionados explicitamente en los instrumentos internacionales sobre derechos humanos están sujetas a un grado de escrutinio especialmente estricto, en virtud de lo cual los Estados deben aportar un interés particularmente importante y una justificación cabal de la distinción". ${ }^{71}$

Asimismo, la Corte IDH ha también exigido un "test estricto de análisis", por considerar que se encontraba en juego un criterio de discriminación prohibido por el artículo 1.1. de la Convención, interpretando el criterio "cualquier otra condición social". ${ }^{72}$

Por otra parte, dicho examen riguroso de razonabilidad o escrutinio estricto también debería ser aplicado por cuanto el ejercicio del derecho a la objeción de conciencia constituye una modalidad del ejercicio de las libertades de conciencia y religión, expresamente consagradas en el artículo 12 de la Convención Americana sobre Derechos Humanos.

Si bien la Corte IDH no se ha pronunciado expresamente sobre la interpretación de dicho artículo, sí lo ha hecho con relación al artículo 13.2., sobre libertad de pensamiento y de expresión, que se encuentra redactado de modo similar al artículo 12.3, por lo que los criterios allí señalados resultarian extrapolables al derecho a la libertad de conciencia y religión. ${ }^{73}$

El artículo 12.3. de la precitada Convención establece:

La libertad de manifestar la propia religión y las propias creencias está sujeta únicamente a las limitaciones prescritas por la ley y que sean necesarias para proteger la seguridad, el orden, la salud o la moral públicos o los derechos o libertades de los demás.

El artículo 13.2. prescribe:

El ejercicio del derecho previsto en el inciso precedente no puede estar sujeto a previa censura sino a responsabilidades ulteriores, las que deben estar expresamente fijadas por la ley y ser necesarias para asegurar: a) el respeto a los derechos o a la reputación de los demás, o b) la protección de la seguridad nacional, el orden público o la salud o la moral públicas.

Al respecto, siguiendo a la Corte Europea de Derechos Humanos, la Corte IDH entendió que el término "necesarias" implica la existencia de una necesidad social

dencial, resulta justificado afirmar que para dicha Comisión el derecho a la objeción de conciencia emana del artículo 12 de la Convención Americana sobre Derechos Humanos.

71 CIDH, Informe sobre terrorismo y derechos humanos, OEA/SER.L/V/11.116, Doc. 5 rev. 1 corr., 22

27472 Cfr. Corte IDH, “Atala Riffo y Niñas vs. Chile”, sentencia del 24-02-2012, párrafos 83 a 93 y 131.

73 Al respecto cfr. Fernando Arlettaz, "La libertad religiosa en el sistema interamericano de derechos humanos”, Revista Internacional de Derechos Humanos, 1 (2011), p. 52. 
imperiosa, por lo que las restricciones o limitaciones a la libertad de expresión -y se podría afirmar también a la libertad de conciencia y religión- deben estar orientadas a satisfacer un "interés público imperativo". Agregó también, que "entre varias opciones para alcanzar ese objetivo debe escogerse aquella que restrinja en menor escala el derecho protegido", concluyendo en que "la restricción debe ser proporcionada al interés que la justifica y ajustarse estrechamente al logro de ese legitimo objetivo". ${ }^{74}$

Los estándares transcritos en el párrafo precedente suponen adoptar un examen de razonabilidad intensivo, cuyos juicios se asemejan tanto al escrutinio estricto aplicado por la Corte Suprema de Estados Unidos, como al test de constitucionalidad aplicado por la Corte Suprema de Argentina, en los supuestos de distinciones de trato basadas en alguno de los criterios expresamente prohibidos por los Tratados Internacionales de Derechos Humanos con jerarquía constitucional. A tenor de los argumentos expuestos, cabe afirmar que, en el orden jurídico argentino, para convalidar la constitucionalidad de la norma o práctica que deniega el ejercicio de la objeción de conciencia, se deben superar:

3.1. En primer lugar, el juicio de adecuación, requiriéndose que la obligación objetada que se pretende imponer persiga un objetivo legítimo y resulte idónea para alcanzarlo, no bastando una genérica adecuación a los fines, sino su promoción efectiva. O sea, la obligación ha de estar directamente vinculada con los objetivos buscados. ${ }^{75}$

3.2. En segundo lugar, el juicio de necesidad, conforme al cual la denegación del ejercicio de la objeción de conciencia ha de constituir el único medio disponible y eficaz para alcanzar la finalidad perseguida mediante la imposición de la obligación. Ello implica considerar la existencia de otras medidas alternativas e igualmente idóneas para la realización del fin pretendido, de modo tal que resulte posible mantener incólume la conciencia del objetor y al mismo tiempo alcanzar el objetivo buscado. ${ }^{76}$

3.3. En tercer lugar, el juicio de proporcionalidad en sentido estricto, por el que la obligación objetada deberá dirigirse a la obtención de un fin imperioso o sustancial, no bastando que sea legitimo o meramente conveniente. ${ }^{77}$ Esto supone efectuar un control intensivo de la proporcionalidad en sentido estricto, practicado desde la perspectiva del tribunal, no resultando suficiente un control de evidencia efectuado desde la perspectiva del legislador. ${ }^{78}$

74 Corte IDH, "La Colegiación obligatoria de periodistas (arts. 13 y 29 Convención Americana sobre Derechos Humanos)”, opinión consultiva 5/85 (13-11-1985), párr. 46.

75 Cfr. "Hooft”, Fallos 327:5118 (2004); "Gottschau”, Fallos 329:2986 (2006) y "Mantecón Valdés", Fallos 331:1715 (2008).

76 Cfr. "Hooft”, Fallos 327:5118 (2004); “Gottschau”, Fallos 329:2986 (2006); “Mantecón Valdés”, Fallos 331:1715 (2008) y "Partido Nuevo Triunfo", Fallos 332: 433 (2009).

77 Cfr. idem.

78 Sobre los dos niveles de control de la proporcionalidad en sentido estricto cfr. Carlos Bernal PuLIDo, El principio de proporcionalidad y los derechos fundamentales, op. cit., p. 796. 
3.4. En cuarto lugar, complementando el examen de proporcionalidad en sentido estricto, y en consonancia con lo señalado en el apartado 1.4., entiendo que debe ser aplicado el juicio de alteración del contenido esencial del derecho fundamental en juego, ${ }^{79}$ de modo tal que se mantenga inalterable la sustancia del derecho a la objeción de conciencia, evitando que mediante la invocación de intereses estatales imperiosos se lo violente. A los fines de determinar el contenido esencial deberá tenerse presente que el bien humano, objeto del mencionado derecho fundamental, está constituido por la razonabilidad práctica, la que entre sus exigencias impone seguir la propia conciencia, no atentar directamente contra un bien humano y procurar el bien común de las propias comunidades. ${ }^{80}$ Por ello, no se considerará incluido dentro del contenido esencial del derecho a la objeción de conciencia el acto que, mediante el incumplimiento de una obligación, suponga un atentado directo contra un bien humano o contra el bien común, no evitable por otros medios.

Finalmente, tal como se sostuvo en el apartado 2, por las razones allí señaladas, la carga de la justificación deberá imponerse sobre el Estado o la persona que deniegue el ejercicio de la objeción de conciencia, a quienes corresponderá demostrar que dicha denegación logra sortear los juicios de adecuación, necesidad, proporcionalidad en sentido estricto y alteración del contenido esencial, con los alcances y el grado de intensidad especificados en los párrafos precedentes. Dicha carga, cuando la objeción de conciencia se plantea por razón de la religión, también debe ser impuesta sobre quien se opone al ejercicio del mencionado derecho, por estar en juego un criterio de discriminación expresamente prohibido por los Tratados Internacionales de Derechos Humanos, criterio cuya utilización o aplicación se presume inconstitucional, según lo ha resuelto el Máximo Tribunal argentino. ${ }^{81}$

\section{CONCLUSIONES}

Llegados a este punto, corresponde exponer las conclusiones que pueden extraerse de las ideas desarrolladas precedentemente, a saber:

4.1. El reconocimiento del derecho a la objeción de conciencia supone adoptar un concepto de derecho no legalista, por el que la ley no es todavía el derecho, sino más bien, al decir de Villey, un proyecto de derecho, por lo que la objeción de conciencia, no obstante implicar el incumplimiento de un deber impuesto por una norma constitucional, legal, reglamentaria o convencional, no será una conducta antijurídica, cuando su ejercicio es razonable o regular.

79 Con respecto al juicio de alteración del contenido esencial cfr. Juan CIANCIARDo, El principio de razonabilidad, op. cit., pp. 94-102.

81 Cfr. "Hooft", Fallos 327:5118 (2004); “Gottschau”, Fallos 329:2986 (2006); "Mantecón Valdés", Fallos 331:1715 (2008) y "Partido Nuevo Triunfo”, Fallos 332: 433 (2009). 
4.2. Una vía para la determinación de lo que se ha de considerar el ejercicio razonable del derecho a la objeción de conciencia lo constituye el principio de razonabilidad, denominado en el derecho continental europeo principio de proporcionalidad. Dicho principio, según el desarrollo de la doctrina y jurisprudencia alemana, se compone de tres subprincipios o juicios: adecuación, necesidad y proporcionalidad en sentido estricto.

4.3. La aplicación del juicio de adecuación en los casos donde se pretende el ejercicio de la objeción de conciencia supondrá determinar cuál es la finalidad perseguida mediante la obligación incumplida por el objetor, si dicha finalidad es legitima y si la obligación objetada resulta idónea o adecuada para alcanzarla en las concretas circunstancias de la causa.

4.4. Una vez sorteado el juicio de adecuación, será preciso preguntarse por la necesidad o indispensabilidad del deber que ha de ser cumplido por el objetor, como así también por la existencia de otras medidas alternativas y menos restrictivas, que preserven la libertad de conciencia o religión de este último y, al mismo tiempo, resulten idóneas para alcanzar el objetivo perseguido mediante dicho deber.

4.5. El juicio de proporcionalidad en sentido estricto implicará sopesar el grado de perjuicio al fin de bien público o de restricción de las normas iusfundamentales que provoca el incumplimiento de la obligación objetada. De tal modo, será preciso considerar si los beneficios obtenidos mediante la exigencia de cumplimiento del deber objetado son proporcionalmente mayores a los costos que supone una denegación de la pretensión de ejercer la objeción de conciencia.

4.6. A los fines de no incurrir en un análisis utilitarista, el juicio de proporcionalidad en sentido estricto debe ser complementado con el juicio de alteración del contenido esencial del derecho fundamental en cuestión. En el caso del derecho a la objeción de conciencia, para la determinación de su contenido será preciso considerar, entre otras cuestiones, los bienes humanos a los que este se ordena. Tomando en cuenta la clasificación de bienes humanos propuesta por Finnis, tales bienes pueden ser identificados como la "razonabilidad práctica" y la "religión".

4.7. Desde la perspectiva señalada en la conclusión 4.6., no constituirán un ejercicio razonable de la objeción de conciencia aquellas acciones por las que el objetor atente directamente contra un bien humano básico, dañándolo o impidiendo a otros su participación en dicha forma de bien humano. Asimismo, no estarán comprendidas dentro de la esfera de funcionamiento razonable del derecho aquellas conductas que resulten contrarias al bien común. Todas estas consideraciones deberán ser efectuadas en las concretas circunstancias de la causa, más que de modo apriorístico o abstracto.

4.8. La jurisprudencia de la Corte Suprema de Argentina, de Estados Unidos y del Tribunal Europeo de Derechos Humanos han aplicado el principio de razonabilidad para juzgar casos en los que se invocó el ejercicio del derecho a la objeción de conciencia. 
4.9. Con sustento en la jurisprudencia de la Corte Suprema de Argentina y de la Corte Interamericana de Derechos Humanos, resulta plausible afirmar que en el ordenamiento jurídico argentino debe aplicarse un examen intensivo de razonabilidad o un escrutinio estricto, en aquellos supuestos donde se deniega el ejercicio de la objeción de conciencia.

4.10. El escrutinio estricto implicará también un desplazamiento de la carga de la justificación sobre quien se opone al ejercicio de la objeción de conciencia. Ello significa que el objetor solo debe exponer las razones éticas o religiosas que sustentan su oposición al cumplimiento de una obligación constitucional, legal, reglamentaria o convencional, las que deben ser sinceras y responder a un sistema de pensamiento coherente e inteligible. Luego, quien rechace el planteo del objetor deberá acreditar los extremos indicados en el apartado 2 .

\section{BIBLIOGRAFÍA}

AlEXY, Robert, Teoría de los derechos fundamentales, Madrid, Centro de Estudios Constitucionales, trad. de Ernesto Garzón Valdés, 1993.

ARISTÓTELES, Ética Nicomaquea.

ARLETTAZ, Fernando, "La libertad religiosa en el sistema interamericano de derechos humanos”, en Revista Internacional de Derechos Humanos 1 (2011), pp. 39-58.

BARNES, Javier, "Introducción al principio de proporcionalidad en el derecho comparado y comunitario”, en Revista de Administración Pública, 135 (1994), pp. 495-522.

Bernal Pulido, Carlos, El principio de proporcionalidad y los derechos fundamentales. El principio de proporcionalidad como criterio para determinar el contenido de los derechos fundamentales vinculante para el legislador, Madrid, Centro de estudios políticos y constitucionales, 2003.

Boyle, Joseph, Grisez, Germain y Finnis, John, "Practical Principles, Moral Truth, and Ultimate Ends", en Scholarly Works, 846 (1987), en http://scholarship. law.nd.edu/law_faculty_scholarship/846.

Carbonell Miguel (coord.), El principio de proporcionalidad en el Estado Constitucional, Bogotá, Universidad del Externado, 2007.

Cianciardo, Juan, El principio de razonabilidad. Del debido proceso sustantivo al moderno juicio de proporcionalidad, Buenos Aires, Ábaco de Rodolfo Depalma, 2004.

Clerico, Laura, El examen de proporcionalidad en el derecho constitucional, Buenos Aires, Eudeba, 2009.

Contreras Mazarí, José María, "Libertad de conciencia y convicción en el sistema constitucional español”, en Revista CIDOB D`Afers Internationals, 77, pp. 41-63. 
DANDois, Marina, "Los bienes humanos básicos y la fundamentación del derecho. Un estudio de la propuesta de John Finnis”, en Dikaion, 23-1 (2014), pp. 37-53.

DiDier, María Marta, El principio de igualdad en las normas jurídicas. Estudio de la doctrina de la Corte Suprema de Argentina y su vinculación con los estándares de constitucionalidad de la jurisprudencia de la Corte Suprema de Estados Unidos, Buenos Aires, Marcial Pons, 2012.

Didier, María Marta, Romero Esteban, José Ignacio y Parini, Nicolás Francisco, “Objeción de conciencia: un fallo trascendente de la Corte Suprema de los Estados Unidos”, La Ley, 11 de noviembre de 2014, pp. 3-8.

Dworkin, Ronald, A Matter of principle, Oxford University Press, 1986.

Finnis, John, Ley natural y derechos naturales, Buenos Aires, Abeledo Perrot, trad. de Cristóbal Orrego Sánchez, 2000.

Finnis, John y Grisez, Germain, “The Basic Principles of Natural Law: A Reply to Ralph MacInerny”, en American Journal of Jurisprudence 26, (1981), pp. 21-31

Gascón Abellán, Marina, Obediencia al derecho y objeción de conciencia, Madrid, Centro de Estudios Constitucionales, 1990.

Gavara De CARA, Juan Carlos, Derechos fundamentales y desarrollo legislativo. La garantía del contenido esencial de los derechos fundamentales en la Ley Fundamental de Bonn, Madrid, Centro de Estudios Constitucionales, 1994.

Geldi, María Angélica, Constitución de la Nación Argentina. Comentada y concordada, 3 ed., Buenos Aires, La Ley, 2005.

George, Robert P., Making man moral, New York, Oxford University Press, 1993.

George, Robert P., "Those of us who care about religious freedom have a job to do", Vital Speeches of the Day 80, (2014), pp. 35-41.

HervadA, Javier, Lecciones propedéuticas de filosofia del derecho, Pamplona, Eunsa, 1992.

HERvadA, Javier, "Libertad de conciencia y error sobre la moralidad de una terapéutica”, en Persona y Derecho 11 (1984), pp. 13-53.

Kalinowski, George, Concepto, fundamento y concreción del derecho, Buenos Aires, Abeledo Perrot, 1982.

LinARES, Juan Francisco, Razonabilidad de las leyes. El debido proceso como garantía innominada en la Constitución argentina, 2 ed., Buenos Aires, Astrea, 1970.

Martínez ToRRón, Javier, "Una metamorfosis incompleta. La evolución del derecho español hacia la libertad de conciencia en la jurisprudencia constitucional”, en Persona y Derecho 45 (2001), pp. 199-260.

Massini Correa, Carlos Ignacio, Filosofia del derecho, Buenos Aires, Lexis Nexis, 2005. 
Massini Correa, Carlos Ignacio, "La nueva escuela anglosajona del derecho natural”, en Las razones del derecho natural, Renato RABBI BALDI (coord.), Buenos Aires, Abaco, 1998, pp. 255-277.

Massini CorreA, Carlos Ignacio, "El derecho a la vida en la sistemática de los derechos humanos", en El derecho a la vida, Pamplona, Eunsa, 1998, pp. 179-222.

Medina Guerrero, Manuel, La vinculación negativa del legislador a los derechos fundamentales, Madrid, McGraw-Hill, 1996.

Navarro Valls Rafael, y Martínez Torrón, Javier, Conflictos entre conciencia y ley. Las objeciones de conciencia, 2 ed., Madrid, Iustel, 2012.

Nino, Carlos Santiago, Ética y Derechos Humanos. Un ensayo de fundamentación, 2 ed., Buenos Aires, Astrea, 2005.

OlLERo, Andrés, "Soy en realidad iusnaturalista", en http://www.aafder.org/ wp-content/uploads/2015/06/Ollero-Soy-en-realidad-iusnaturalista.pdf, pp. 1-29.

PoRTElla, Jorge Guillermo, La justificación iusnaturalista de la desobediencia civil y la objeción de conciencia, Buenos Aires, Educa, 2005.

Rawls, John, Teoría de la justicia, 2 ed., México, Fondo de Cultura Económica, trad. de M. D. González, 1997.

RAz, Joseph, La autoridad del derecho. Ensayos sobre derecho y moral, $2^{\text {a }}$ edición, México, Universidad Autónoma de México, Imprenta Universitaria, 1985.

Rubio López, José Ignacio, "La última aplicación de la doctrina norteamericana del Strict Scrutiny en el derecho de libertad religiosa: González V. O Centro Espirita”, Ius Canonicum XLVI, 92 (2006), pp. 581-622.

Serna, Pedro y Toller, Fernando M., La interpretación de los derechos fundamentales. Una alternativa a los conflictos de derechos, Buenos Aires, La Ley, 2000.

SoRIANo, Ramón, "La objeción de conciencia: significado, fundamentos jurídicos y positivización en el ordenamiento jurídico español”, en Revista de Estudios Políticos, 58 (1987), pp. 61-110.

Spaemann, Robert, "Sobre el concepto de dignidad humana", en Carlos Ignacio MASsini y Pedro Serna (eds.), El derecho a la vida, Pamplona, Eunsa, 1998, pp. 81-110.

SuAY Rincón, José, El principio de igualdad en la justicia constitucional, Madrid, Instituto de Estudios de Administración Local, 1985.

TolLER, Fernando M., "Los derechos in concert. Metodologias para tomar decisiones armonizadoras en casos entre derechos y bienes constitucionales", en Juan Cianciardo (coord.), Constitución, neoconstitucionalismo y derechos, México, Porrúa, 2012, pp. 111-155.

280 Tribe, Laurence H., American constitutional law, 2 ed., Mineloa, New York, The Foundation Press, Inc., 1988. 
Velázguez Córdoba, Luis Fernando y Córdoba Palacio, Ramón, "Objeción de conciencia y la antropología filosófica”, Persona y Bioética 14, 2, 2010, pp. 167-175.

VIGo, Rodolfo Luis, "Derecho a la objeción de conciencia: implicancias y consecuencias”, El Derecho. Diario de doctrina y jurisprudencia, 28 de agosto de 2015, pp. 1-4.

Vigo, Rodolfo Luis, "Derecho y Moral en el Estado de Derecho Constitucional (Proyecciones teóricas: iuspositivismo, neoconstitucionalismo y realismo jurídico clásico)”, en Prudentia Iuris 74 (2012), pp. 57-78.

VIGo, Rodolfo Luis, Las causas del derecho, Buenos Aires, Abeledo Perrot, 1983.

Villey, Michel, Compendio de filosofia del derecho. Definiciones y fines del derecho, Pamplona, Eunsa, 1979. 